Estudios Fronterizos, vol. 10, núm. 20, julio-diciembre 2009, pp. 129-152

\title{
Participación y deliberación como correctores del sistema democrático
}

\author{
Rodrigo Santiago Juárez*
}

Resumen. Todo régimen democrático debe asegurar que la participación y la representación se constituyan en dos caras de la misma moneda. En muchas de las democracias actuales no se fomenta la participación de los ciudadanos salvo en casos específicos, como en las elecciones periódicas. Por ello es necesario fomentar la participación y la educación en valores cívicos. Finalmente, deben cobrar fuerza las propuestas que buscan la deliberación política, a fin de otorgar legitimidad a la democracia.

Palabras clave: Democracia, liberalismo, republicanismo, ciudadanía, deliberación.

Abstract. Every democratic regime has to guarantee that participation and representation set in both sides of the same coin. In a lot of modern democracies, government doesn't foment citizen participation, or just do it in case of periodic elections. That's why is necessary to foment participation and civic virtues. Finally, we have to support deliberative teories to give legitimacy to our democracies.

Keywords: Democracy, liberalism, republicanism, citizenship, deliberation.

Artículo recibido el 11 de noviembre de 2008 Artículo aceptado el 25 de marzo de 2009

\footnotetext{
* Doctor en Derecho por la Universidad Carlos III de Madrid. Oficina del Abogado General de la Universidad Nacional Autónoma de México. Correo electrónico: ro_santiago@yahoo.com
} 


\section{Sociedad política y sujeto participativo}

La representación política, como la conocemos actualmente, exige ciertos mínimos de participación esenciales al proceso político, y a los que resulta necesario apelar para dotar de cierta legitimidad a su resultado (García-Marzá, 1996:97-121). De esta manera, es fácil comprender por qué en la democracia la participación y la representación, aun siendo procesos distintos, han de darse simultáneamente (Verdú y De la Cueva, 2001:238). ${ }^{1}$

Es necesario llevar a cabo elecciones cuyo resultado dé lugar al nombramiento de los representantes, pero para realizar dichas elecciones se requiere del sufragio de los ciudadanos. Sin tal participación es imposible el nombramiento de los representantes, y si éstos no son elegidos no se puede llevar a cabo la representación de los individuos.

De esta manera, aun separados, ambos conceptos no pueden desvincularse en la práctica política, ya que cada uno requiere de la existencia del otro. "Participación que se vuelve representación gracias al voto, y representación que se sujeta a la voluntad popular gracias a la participación cotidiana de los ciudadanos" (Merino, 1995:27). De ahí que podamos decir que "cuando la representación es participada y la participación es representativa, estamos ante un Estado en cierto modo ideal a cuyo modelo deben acercarse, lo más posible, las comunidades políticas" (Lucas Verdú y Lucas Murillo, 2001:239).

En uno de sus trabajos más reconocidos, Benjamin Constant menciona diferencias fundamentales entre la libertad existente entre los individuos de las antiguas sociedades griegas y los ciudadanos de las sociedades contemporáneas (Constant, 1989). El núcleo de dicho trabajo reside en afirmar que muchos de los derechos de tipo político que gozaban los individuos en aquellas sociedades perdieron importancia

\footnotetext{
${ }^{1}$ Los autores hacen una diferencia entre representación, que consideran un concepto jurídico-político, y la participación, que consideran un concepto político que exige un "consenso generalizado sobre las instituciones establecidas y las pautas de gobierno". De esta manera mencionan: "Una representación será participada cuando la articulación jurídica, establecida por el Estado-aparato, conecte con el Estado comunidad. Una participación será representativa cuando la comunicación entre el Estado-comunidad y el Estado-aparato y las demandas del primero al segundo asciendan con fluidez".
} 
al ser introducidos derechos de otra naturaleza. Con tal introducción se privilegiaron los derechos subjetivos sobre los intereses públicos.

Buena parte de las discusiones que tienen que ver con privilegiar los derechos de tipo individual frente a los derechos de tipo político se basan en esta clara diferencia entre las sociedades antiguas y las modernas, argumentando que sólo pueden protegerse los primeros limitando la acción del Estado y restringiendo los derechos de tipo público.

Algunas posturas filosófico-políticas han establecido la primacía de los derechos fundamentales sobre los referentes a la participación política y a la soberanía popular, considerando que los primeros no pueden depender de la voluntad del pueblo, sino que han de permanecer en una esfera ajena a toda voluntad. Por lo tanto, según ciertos planteamientos de tipo conservador, la ausencia de participación es considerada como algo positivo para los regímenes democráticos (García-Marzá, 2003:113).

Es por eso que si bien las diferentes posturas republicanas y liberales han privilegiado la participación y la soberanía popular, por un lado, y los derechos fundamentales, por otro, Habermas afirma que es momento de superar tales debates y encontrar los puntos en que ambas sean compatibles (Rodríguez Palop, 2002:314)² sin priorizar definitivamente ninguna de ellas (Habermas, 1997:28-30). ${ }^{3}$

La democracia deliberativa que propone otorga un papel fundamental a la participación política a la que apelan las posturas republicanas, agregando la idea de un intenso campo para la deliberación de las ideas, en el que resulten protegidos los derechos de naturaleza individual (Vallespín, 1997:214). Para esto establece que la conexión entre soberanía popular y derechos fundamentales consiste en el hecho de que estos últimos establecen las pautas en las cuales las diversas formas de comunicación que se requieren para llevar a cabo un proce-

\footnotetext{
${ }^{2}$ La autora señala que "frente al republicanismo y al modelo liberal, puede presentarse como una vía intermedia la teoría discursiva habermasiana".

${ }^{3}$ Según el filósofo alemán, el nexo interno entre derechos humanos y soberanía popular consiste en que a través de los derechos humanos deben cumplirse las exigencias de una institucionalización jurídica, de una praxis ciudadana del uso público de libertades comunicativas. Derechos humanos que posibiliten el ejercicio de la soberanía popular no pueden ser impuestos a esta praxis como una limitación de fuera.
} 
so legislativo autónomo pueden ser correctamente institucionalizadas, dando lugar a lo que es posible considerar una verdadera soberanía popular (Habermas, 2004:205-206).

En sus trabajos sobre liberalismo y democracia, Bobbio también señaló que las discusiones en las que se pretendían defender los postulados liberales por un lado, y los democráticos por otro, terminaban reconociendo que ambas mantenían intensas coincidencias. Asegura así que "sin libertades civiles, como la libertad de prensa y opinión, y como la libertad de asociación y de reunión, la participación del pueblo en el poder político es un engaño; pero sin participación del pueblo en el poder, las libertades civiles tienen bien pocas posibilidades de durar" (Bobbio, 1993:117).

Los derechos reconocidos desde las teorías liberales resultan complementarios a los postulados a los que apelan las teorías reconocidas como más democráticas. Son parte de un mismo fenómeno que antes o después requiere de los derechos civiles y de los derechos políticos. Confirmando esa clara vinculación, Bobbio continúa señalando: "Mientras las libertades civiles son una condición necesaria para el ejercicio de la libertad política, ésta, es decir, el control popular del poder político, es una condición para la consecución, primero, y para la conservación, después, de las libertades civiles" (Bobbio, 1993:117-118).

\section{Participación, capital social y democracia}

Como consecuencia de lo hasta aquí planteado, resulta importante mencionar que la participación política viene determinada en gran medida por la forma en que está estructurada la sociedad civil, en la cual se sintetizan los procedimientos de formación de la opinión pública. Tal y como señala Habermas, la sociedad civil está formada por todas aquellas asociaciones, organizaciones y movimientos surgidos de forma más o menos espontánea, que recogen la resonancia de los problemas de la sociedad y los transmiten al espacio de la opinión pública (Habermas, 1998:447).

No todas las organizaciones ciudadanas tienen motivos o fines de influencia puramente política, la variedad de propósitos es tan amplia que resulta absurdo tratar de mencionarlas. Lo importante aquí 
es establecer la importancia que tiene para una sociedad el que sus ciudadanos puedan establecer vínculos con otras personas, y gracias a ello mantener grupos ciudadanos de muy distintos tipos.

Cuando las personas forman parte de una determinada estructura ciudadana ya están actuando bajo un propósito compartido, los lazos que los unen con los demás asociados les brindan certeza y seguridad de contar con más personas que les respaldan, que comparten sus intereses y propósitos, por lo que dichos lazos permiten confiar en otros y en determinado momento compartir los beneficios que les brinde ser parte de dicha agrupación.

El nombre que le podemos dar a lo que se obtiene como resultado de la formación de esta serie de redes y estructuras que forman los integrantes de determinada organización es el de "capital social", concepto que ha sido estudiado por muchos autores y que nos puede ayudar para destacar la importancia de la participación. En este sentido, el capital social será aquel que se forma a partir de la relación existente entre personas o grupos y que permite tener una mayor comunicación entre todos, alcanzando con esto un mejor conocimiento de los problemas que les aquejan y obteniendo resultados que benefician al colectivo, es decir, un bien público.

Coincidiendo con James Coleman, puede decirse que, al igual que los otros tipos de capital, "el capital social es productivo, haciendo posible la consecución de determinados fines inalcanzables sin él" (Coleman, 2001:47-81). Por lo tanto, los fines a los que se puede arribar a través de este capital serán de carácter público. La intensa relación entre personas y organizaciones favorece la creación de un ambiente en el que el individuo se ve confiado a participar, ya que halla a su alrededor organizaciones sociales distintas a los partidos políticos en las que puede encontrar apoyo y compartir puntos de vista con personas interesadas en los mismos asuntos.

En el clásico estudio realizado por Gabriel Almond y Sidney Verba sobre la participación política en cinco naciones, se dieron resultados que pueden ilustrarnos fielmente sobre la forma en la que en estos países los ciudadanos participan en los distintos ámbitos de la vida social. Los resultados obtenidos en los cinco países fueron muy distintos, pero existe una notable diferencia entre naciones como Gran Bre- 
taña y Estados Unidos y otros países, como Alemania, Italia y México. La confianza resultó, en todos los casos, ser un parámetro eficaz para evaluar el grado de participación ciudadana.

En Gran Bretaña y Estados Unidos los niveles de confianza que el ciudadano depositaba en los demás eran mayores que en los otros países, siendo también alta la participación de esos ciudadanos en actividades de tipo social y político. Esto nos demuestra que la valoración que las personas tienen sobre los conciudadanos repercutirá fuertemente en las redes de tipo social que estén dispuestos a formar (Almond y Verba, 1970:302).

La razón por la cual la confianza existe en una sociedad y no en otra puede derivarse de factores culturales, económicos o sociales. Lo que debe quedar claro es que su existencia será determinante para la creación y el desarrollo del capital social y, por lo tanto, para el buen desarrollo de la participación política.

Mencionando diversas cuestiones detonantes de la desconfianza, Ludolfo Paramio señala que han existido cambios en el mundo que han disminuido la confianza de las personas. De acuerdo con su punto de vista, esa desconfianza se traduce en un repliegue hacia nichos mínimos personales o minicolectivos que perjudican seriamente a la economía, a la sociedad y al asentamiento de la democracia (Paramio, 1996:103-114).

Según este autor, es evidente que para que se den ciertos cambios necesarios en la sociedad deben encontrar solución los problemas centrales que atañen a nuestras democracias, ya que sólo de esa forma podrán construirse instituciones y sociedades que permitan alcanzar los objetivos del bien público.

Su razonamiento se centra en el hecho de que antes de lograr construir las nuevas instituciones económicas, sociales y políticas que necesitamos, un primer paso será defender, en el plano de las ideas, la necesidad de reglas e instituciones. Por esto se otorga especial importancia al hecho de que los partidos políticos sean capaces de llegar a acuerdos, de crear relaciones firmes entre ellos en función de un objetivo democrático común, y de crear confianza en los ciudadanos presentando proyectos posibles y acordes con su ideología.

Según Robert D. Putnam, "una sociedad que se basa en la reciprocidad generalizada es más eficiente que una sociedad plagada de des- 
confianza, por la misma razón que el dinero es más eficiente que el trueque. La confianza es el lubricante de la vida social". La importancia de contar con distintos tipos de organizaciones que refuercen el entramado social es vital para consolidar sistemas democráticos y para incentivar actitudes de confianza. Para muchos teóricos de la democracia, es importante buscar soluciones más allá de las instituciones políticas comunes, y enfocar su atención en la sociedad civil y en el trabajo que la misma desempeña en la consecución del bien público.

La aportación que esas organizaciones brinden a la economía, a la política y a la democracia se verá reflejada en impulsos en estos tres sectores, que darán en su momento los resultados deseados. Según Putnam, el capital social incorporado en normas y redes de compromiso cívico "parece ser una precondición para el desarrollo económico, así como para un gobierno efectivo" (Putnam, 2001:89-104).

No obstante, como veremos a continuación, muchos autores continúan señalando que el sistema de representación y la democracia procedimental no requiere de ningún tipo de cambio, por lo que ponen en duda la validez de muchas de las propuestas de profundización democrática.

\section{El ciudadano en la democracia procedimental}

Ciertos condicionantes influyen directamente en el desarrollo de la democracia, y determinan en gran medida la formación de los ciudadanos que habitan en las sociedades democráticas. Circunstancias tales como la educación, el ejercicio de los derechos y libertades cívicas, la seguridad jurídica, y la influencia de los medios de comunicación, inciden de forma directa en la apatía o interés que muestren los ciudadanos respecto a temas comunes.

Giovanni Sartori ha asegurado que algunas posturas que pretenden modificar el sistema de la representación política por modelos alternativos en los que se implementen mecanismos de democracia directa no tienen ninguna posibilidad de funcionar, ya que el ciudadano no cuenta con la preparación suficiente para tomar determinadas decisiones (Sartori, 1999:2-6). Se podría suponer que después de presentar intensas críticas contra las propuestas alternativas de de- 
mocracia, este autor ofrecería un catálogo de las virtudes de la representación política, pero no es así. Se limita, por el contrario, a señalar una característica que lejos de resultar fundamental como defensa de sus planteamientos, nos convence de que algo tiene que cambiar.

De esta manera, asegura que la democracia representativa, a diferencia de la directa, exige mucho menos del ciudadano y puede operar aunque su electorado sea "mayoritariamente analfabeto, incompetente o esté desinformado; circunstancias que una democracia directa no podría enfrentar sin estar condenada al fracaso" (Sartori, 1999:2-6). Esta justificación, lejos de servir como una razón de peso para creer en la representación como modelo idóneo, nos confirma el desencanto que impera en el momento actual, así como el convencimiento pleno de que las cosas van por mal camino.

Pudiera entenderse que Sartori está convencido de que las propuestas que promueven lo que él denomina "directismo" tuvieran como propósito la abolición de todo el sistema representativo y la adopción de decisiones exclusivamente mediante la democracia directa. Cabe decir que el mismo Rousseau, después de definir el tipo de sistema político que de mejor forma podía dar cabida a la injerencia popular en las decisiones del gobierno, advirtió que: "Si hubiese un pueblo de dioses, se gobernaría democráticamente. Mas un gobierno tan perfecto no es propio de los hombres" (Rousseau, 1988).

Es difícil suponer que Sartori no reconozca que las posturas alternativas sobre democracia van más allá de la simple vuelta a métodos de democracia directa o modelos de tipo comunista basados en la obra de Marx (Sartori, 1993:241). ${ }^{4}$ De hecho, lo que promueven las modernas propuestas es que la representación se corrija mediante instrumentos de participación y deliberación política. Por lo tanto, lo que se pretende con ellas no es que todas las decisiones se tomen por la totalidad del pueblo reunido en una asamblea ni que se llegue a fin de cuentas a una dictadura del proletariado.

Como aclara Rubio Carracedo, "ni siquiera los promotores de la democracia directa buscan resucitar la democracia asamblearia

\footnotetext{
${ }^{4} \mathrm{El}$ análisis del autor se centra, de hecho, en las alternativas que ofrecen los modelos de Rousseau y Marx, lo que lo lleva a afirmar que no hay la alternativa posible a la democracia liberal.
} 
ateniense, que desde Tucídides ha sido desacreditada" (Rubio Carracedo, 2000:76). Es ilógico pensar, siguiendo la postura de Schattschneider, que los gobiernos pueden ser administrados según las ideas de los filósofos predemocráticos que ni siquiera tuvieron la oportunidad de ver este modelo político llevado a la práctica, por lo que el papel de los teóricos hoy debería consistir en aportar nuevas ideas que puedan mejorar la realidad, y no en lamentarse de realidades que no pertenecen a estos tiempos (Schattschneider, 1960:30).

Si se reconoce que en las actuales circunstancias la población está desinformada, no se está lejos de saber que uno de los problemas que requiere de una solución inmediata es el de paliar esa desinformación $\mathrm{y}$ esa ignorancia mediante instrumentos educativos $\mathrm{y}$, por lo tanto, mediante el intercambio de información y puntos de vista con la población.

En cierta forma esto lo señalan también los mismos defensores del sistema representativo actual, tal y como ocurre con Francisco Laporta, quien considera que las conductas que se desarrollan dentro y fuera de la democracia arrojan unos resultados muy pobres. Pero al mismo tiempo destaca que la democracia representativa de partidos no es lo que funciona mal ni tiene ningún déficit intrínseco, sino que es el propio demos y sus comportamientos lo que no satisface a los propios defensores de este sistema político (Laporta, 2000:21-26). A su vez, asegura que sólo cuando surjan unos ciudadanos reflexivos y maduros, conscientes de sus deberes cívicos y capaces de representarse en los intereses de los demás, podremos empezar a hablar de la deliberación y la reflexión como sustancia del proceso político y de la virtud cívica como presupuesto de una comunidad política avanzada (Laporta, 2001:22-28).

No obstante, resulta claro que los ciudadanos reflexivos y maduros no surgirán por creación espontánea, ni como resultado de las prácticas democráticas actuales. Por el contrario, sólo podrán surgir y formarse mediante una educación intensa de la cultura cívica, y en condiciones en las que puedan involucrarse en los asuntos públicos (Pateman, 1970:22).

Así las cosas, si los detractores de las propuestas alternativas de la democracia consideran que el pueblo es el culpable de la situación 
actual, ¿qué es lo que proponen?, ¿acaso la solución a tal problema se encuentra en distanciar aún más al pueblo de las decisiones políticas? Como señalan Gargarella y Ovejero, la defensa de la democracia representativa resulta complicada cuando se desconfía de los representados.

Ellos aseguran que esta desconfianza puede llevar a pensar que la forma de salvar la democracia es disminuyéndola, que la forma de preservar los valores es alejarlos de las sociedades que deben cultivarlos (Gargarella y Ovejero, 2000:10-18). Evidentemente, la respuesta no se encuentra en alejar al ciudadano de las decisiones ni en limitar los espacios de decisión a una determinada élite política (Bachrach, 1973:20-21).

Si bien es cierto que el demos de las democracias representativas ha sufrido una apatía y un desinterés respecto al ejercicio de la cultura cívica, esto ocurre, precisamente, por el modelo tradicional de gobernar. La pregunta de Rubio Carracedo parece muy precisa: ¿Quién ha persuadido a los ciudadanos durante los dos últimos siglos para que dejasen los asuntos públicos al cuidado de una clase profesional y se dedicasen enteramente a los negocios y al disfrute de la vida privada, porque cada cuatro años serían libres para reelegir o no a sus gobernantes? (Rubio Carracedo, 2000:21).

El análisis lleva a la respuesta que parece más lógica y, sobre todo, más justa; y es que es el propio modelo político el que ha dado todas las facilidades para que el individuo se desprenda del vínculo respecto a los problemas públicos en el afán de librarlo de toda obligación o responsabilidad. Si se entienden estos antecedentes no es difícil señalar que "después de más de dos siglos de democracia liberal ilustrada y de legitimación representacional, el pueblo no puede ser el culpable, porque de eso se trataba justamente; de mantener a los ciudadanos en una minoría de edad política permanente" (Rubio Carracedo, 2000:21-22). Por ello es injusto atribuir los males de la democracia a la sociedad. Por el contrario, la responsabilidad de los juristas y de los teóricos de la democracia debe centrarse en contribuir al estudio de todos estos problemas y proponer aquellas medidas que desde su punto de vista puedan mejorar las condiciones en las que actualmente trabajan las instituciones democráticas.

Lo que se pretende con algunas de las nuevas propuestas democráticas que promueven la participación y la deliberación, es que los 
ciudadanos se involucren en mayor medida en los asuntos públicos. No podemos incurrir en el error a que hacía referencia Bobbio sobre la tajante separación entre las democracias directa y representativa en sus formas puras (Bobbio, 1985:66), sino ubicarnos en el camino de tránsito que existe entre una y otra para extraer aquello que puede mejorar las condiciones democráticas.

Evidentemente, el ingrediente de la educación en los valores cívicos será de fundamental importancia para la formación de individuos más ilustrados políticamente (Dahl, 1999:208-212), pero a la misma debe agregarse también la participación en foros y deliberaciones públicas con miras a mejorar la base cívica de la democracia (Giner, 2000:160). La promoción de una mayor deliberación no se refiere al ámbito exclusivo de los representantes, sino a la generalidad de los participantes de la política que, en este nuevo panorama, necesita de la presencia y actividad constante del ciudadano (Gargarella y Ovejero, 2000:11).

Esto es lo que las autoridades y los gobiernos democráticos deberían tomar en cuenta, ya que la idea principal de toda democracia se basa en una mayor participación del pueblo en las decisiones del gobierno y sólo mediante su fomento se podrán crear regímenes democráticos que sean acordes con los mismos principios que los fundamentan (Giner y Sarasa, 1995:71).

Mientras más alta sea la participación política mayor será el grado de control y vigilancia que sobre las autoridades y los partidos políticos ejerza la ciudadanía. Es por eso que la participación debe efectuarse en dos sentidos, tanto en la sociedad civil, donde se ejercen las relaciones humanas cotidianas, como en el Estado, en donde se ejerce la ciudadanía y la construcción de las instituciones políticas (Fernández, 1996:129). Por lo tanto, no podemos entender la participación social sin poner un especial interés en las características de aquellos individuos que integran esa sociedad.

Es fácil admitir que en muchas de las ciencias modernas se ha prestado especial atención al estudio de las sociedades políticas por un lado, y a la relación que guardan los ciudadanos frente al poder político, por otro.

El ámbito que se considera menos estudiado es el relativo a la actividad política del ciudadano común y al desarrollo de sus facultades 
y virtudes (Giner, 2000:148-149). En lo que sigue se analizan los diferentes tipos de cultura política existentes en la sociedad para visualizar las características propias del ciudadano de las democracias actuales.

\section{Cultura política y fomento de los valores cívicos}

La cultura política del ciudadano es aquella que va a determinar el grado de participación que dicho sujeto desarrolle dentro del sistema democrático. En el trabajo de Almond y Verba mencionado anteriormente, se destacaron los tres principales tipos de cultura política, entendida ésta como "la particular distribución de las pautas de orientación hacia objetos políticos entre los miembros de una nación". Según su postura, las distintas formas de participación dan lugar a los distintos tipos de cultura política de cada individuo: parroquial, de súbdito y de participante, mismas que pueden existir de conformidad con las sociedades analizadas.

En este orden, la cultura política parroquial se refiere a los individuos que se desarrollan en sociedades donde no existen roles claros de liderazgo, donde las orientaciones políticas hacia dichos roles no se hallan separadas de sus orientaciones religiosas y sociales. "El individuo, en este caso, no espera nada del sistema político". El sujeto con una cultura política parroquial habita en sociedades donde no se encuentran claramente establecidos los órganos de poder, y donde no se requiere ningún tipo de participación al carecer de una autoridad determinada.

En segundo lugar, se encuentra la cultura política de súbdito, entendida como aquella en la que el individuo "tiene conciencia de la existencia de una autoridad gubernativa especializada; está afectivamente orientado hacia ella, tal vez se siente orgulloso de la misma, tal vez le desagrada; y la evalúa como legítima o ilegítima [...] consiste, esencialmente, en una relación pasiva". En las sociedades modernas la cultura política de súbdito se refleja claramente en aquel individuo cuya participación es nula o casi nula, caracterizado por su apatía frente a los temas de interés político. Si los individuos sólo participan en las elecciones se puede decir que su cultura política es de súbdito. 
En tercer lugar, se menciona a la cultura política de participante, donde los individuos "tienden a estar orientados hacia el sistema como un todo y hacia sus estructuras y procesos políticos y administrativos. Los diversos individuos de este sistema político de participación pueden hallarse orientados favorable o desfavorablemente hacia las diversas clases de objetos políticos" (Almond y Verba, 1970:34-36).

Como podemos observar, los habitantes de una determinada sociedad demuestran su interés o desinterés en los temas públicos de muy distintas maneras. Desde luego que estas tres variantes no representan todas las posturas o formas existentes dentro del cuerpo social, pero pueden sernos de gran utilidad para diferenciar estos tipos de carácter cívico.

Según otros autores, las distintas clases de cultura política no pueden ser vistas desde una perspectiva unidimensional, por lo que ofrecen un esquema en el que muestran las diferentes funciones que respecto a la política ejercen los ciudadanos. En este sentido proponen dos grandes grupos; el primero integrado por los apáticos o inactivos, dentro de los que se encuentran aquellos que no ejercen ninguna actividad política o que se limitan a votar regularmente en las elecciones; el segundo grupo está integrado por los políticamente activos, que distinguen entre convencionales y no convencionales.

A su vez, señalan que el subgrupo de los participantes convencionales se encuentra integrado por: 1 . los comunicadores; 2. los que pertenecen y ejercen funciones dentro de un partido político; $\mathrm{y} 3$. aquellos activistas sociales que trabajan dentro de una comunidad. Por su parte, afirman que los participantes no convencionales son aquellos activistas que se reúnen para realizar una protesta pública, los que rechazan a través de mítines políticos la aprobación de una ley, o los que protestan por la situación económica o a favor del respeto de los derechos fundamentales (Milbrath y Goel, 1977:18-19). De lo anterior podemos advertir que la confianza y la motivación con la que cuenten los individuos en las sociedades democráticas es un factor determinante para su propia cultura política y, por lo tanto, se relaciona con el grado de participación que mantengan y la forma en que la lleven a cabo (Bobbio, Matteucci y Pasquino, 1998:1137-1140). 
Como se ha mencionado, en buena parte de las sociedades modernas la participación de las personas se realiza en términos muy escasos o manteniendo niveles mínimos. El momento en el cual la sociedad es llamada a participar se realiza exclusivamente cuando se lleva a cabo la elección de sus representantes políticos. Diferentes posturas apelan a la participación como el mejor mecanismo para que el individuo recupere las potestades que le fueron arrebatadas por el Estado y por otros factores de poder, que con el paso del tiempo le han sustituido en la toma de decisiones.

Así, se ha dicho que, "si bien el principio básico de la organización democrática consiste en la elección libre de los representantes políti$\cos$, la participación ciudadana hace posible extender ese principio más allá de los votos. Convertirla en algo más que una sucesión de elecciones y, de paso, enlazar los procesos electorales con las decisiones políticas cotidianas" (Merino, 1995:14).

Si bien existe un control sobre los poderes del Estado, el verdadero control de los mismos proviene del interés que la sociedad muestre en el actuar de las autoridades cuando el individuo haga valer sus derechos y ejerza sus obligaciones. Este control sólo puede llevarse a cabo a partir de la participación intensa de la sociedad y mediante los canales de deliberación que se proponen como mecanismos de control político (Giner, 2000:167).

Si el pueblo se interesa por las actividades del gobierno y participa señalando las faltas y los defectos en los que tal gobierno incurre, mejorará el desempeño de los actores políticos y las decisiones que se tomen no serán exclusivamente las que mejor convengan a los intereses de una clase política sino, principalmente, aquellas que beneficien al grupo de población que lo requiera, o a su totalidad. Para Mauricio Merino, la participación es indispensable para integrar la representación de las sociedades democráticas a través de los votos, pero una vez constituidos los órganos de gobierno la participación se convierte en el método privilegiado de la llamada "sociedad civil" para hacerse presente en la toma de decisiones políticas (Merino, 1995:29).

La postura republicana de Philip Pettit también se interesa en la sociedad civil como aquella que de mejor manera puede impulsar cambios en el sistema democrático. De esa manera, su postura sobre la 
contestatory democratization se basa en la importancia que tiene otorgar a la sociedad mecanismos mediante los cuales pueda emitir su opinión sobre alguna propuesta legislativa o decisión gubernamental.

El autor considera que a diferencia de lo que sucede en la tradicional democracia electoral, que facilita una participación indirecta del pueblo en la creación de las leyes (a través de los representantes), el modelo por él defendido brinda poderes limitados e indirectos en los que las leyes pueden ser modificadas por la ciudadanía a partir de ciertos foros creados con ese fin (Pettit, 2001:180).

En este sentido, son muchas las propuestas que en la filosofía política se han planteado con el objetivo de otorgar una participación más amplia a la sociedad civil por lo que hace a las leyes y las decisiones gubernamentales. Si tradicionalmente las decisiones de poder político en las democracias representativas se han tomado por un grupo reducido de personas (los representantes y, principalmente, la cúpula de los partidos políticos), el fomento de la participación pretende abrir espacios para que el ciudadano influya en tales decisiones.

En opinión de Amartya Sen, el voto no es suficiente para satisfacer las necesidades de la democracia, ya que al mismo debe añadirse la capacidad de exponer las ideas y escuchar a los demás en un ambiente y en unos términos adecuados. Según este autor, los sistemas no pueden denominarse democráticos si encuentran su legitimación únicamente a través del ejercicio del sufragio, y es por eso que la participación y el intercambio de argumentos en foros deliberativos adquieren una importancia capital.

Desde su punto de vista, las elecciones por sí solas pueden ser lamentables en regímenes autoritarios donde la falta de información, la ausencia de oposición política y las violaciones de los derechos fundamentales obstruyen la verdadera libertad que debe existir al emitir el voto, y por lo tanto, limitan el camino hacia la búsqueda de otros medios de participación política que legitimen esos sistemas políticos (Sen, 2004:13).

Si el voto ciudadano requiere de ciertas condiciones de libertad para que el sistema pueda suponerse como legítimo, una de las condiciones que se debe asegurar es la que tiene que ver con la libertad para exponer los diferentes puntos de vista, y que los mismos puedan ser discutidos ante un foro público (Sen, 2001:10-28). 
En el mismo sentido, Nino asegura que las demandas sociales no deben ser suprimidas limitando la participación, sino que tal participación tiene que funcionar como una válvula de escape permitiendo además que influya en el mecanismo de la toma de decisiones (Nino, 1986:136). La democracia necesita protegerse desde muy distintos frentes y uno de ellos es asegurar que los ciudadanos cuenten con las garantías y los derechos que les permitan una participación plena en los asuntos públicos. En definitiva, más allá del derecho al voto se encuentra toda una serie de derechos que deben ser protegidos (Sen, 2001:8).

La libertad de expresión, por ejemplo, no puede consistir exclusivamente en que la autoridad remueva los obstáculos de censura, ni que el derecho aparezca protegido por una norma. Se requiere además que los individuos que pretenden participar y ser escuchados puedan hacerlo en igualdad de circunstancias (García-Marzá, 2003:114).

Como señala Nino:

Si el debate público requiere que uno se ponga de pie sobre un cajón de manzanas a modo de tribuna, uno debe tener acceso a éste. Si se requiere un micrófono, se necesita un micrófono. Si lo hace por radio o televisión, uno debe tener acceso a estos medios. De forma similar, las personas que no están educadas, o no tienen una vivienda apropiada, no pueden participar completamente o, al menos, igualmente en el proceso de deliberación colectiva y de decisión mayoritaria (Nino, 1997:193).

Resulta claro que muchas de las ideas que tienen que ver con la participación política de los individuos se relacionan con el fomento de las deliberaciones que, impulsadas dentro y fuera del poder político, podrían ser la solución de algunos de los problemas a los que se enfrentan las democracias actuales.

\section{La deliberación como profundización democrática}

Las distintas posturas filosófico-políticas otorgan una importancia diferente al origen del fundamento moral en el que se basan las normas y las decisiones del poder político. Mientras algunas reconocen que el 
individuo autónomo está capacitado para llevar a cabo el análisis racional de determinadas normas de justicia, otras otorgan una importancia mayor a la obtención de decisiones a través de procesos de comunicación intersubjetivos. Estas últimas mantienen que las diferencias o discrepancias morales originadas dentro de una sociedad no pueden resolverse cuando se toma en cuenta exclusivamente uno de los puntos de vista en cuestión, sino que es necesario que en el momento de decidir se sopesen y valoren las distintas opiniones (Asís, 2001:27).

El punto de vista de algunos académicos se dirige a privilegiar la deliberación como el mecanismo apropiado para solucionar las discrepancias morales de los individuos, no únicamente tomando en cuenta el resultado final de los trabajos legislativos, sino el proceso previo a la toma de decisiones (Gutmann y Thompson, 1997:4). ${ }^{5}$ Otros, por el contrario, reconocen que la ley no requiere ningún tipo de fundamento moral, ${ }^{6}$ ya que es aprobada por una autoridad capacitada para ello.

Es decir, el derecho, según esta concepción, no guarda relación alguna con la moral, ni depende de ella para la consecución de sus fines (Asís, 2001:16); al resultar independiente de cualquier análisis moral, el derecho adquiere legitimidad por ser positivo (Nino, 1983:11-50).

Frente a esta postura se han planteado interesantes críticas. Como considera Robert Alexy, el argumento positivista del derecho incurre en errores al pretender legitimar un sistema jurídico simplemente a través de la existencia de la norma, y es por eso que considera que la diferencia entre un sistema de reglas y otro tipo de sistema que legitime situaciones injustas es que el primero cuenta con una pretensión de corrección, es decir, aquella que conecta el derecho y la moral (Alexy, 1998:115-137).

En este sentido, se ha dicho que existen dos posturas por las que se justifica la democracia según el valor que se le conceda a la moral. La primera de ellas simpatiza con el reconocimiento de los derechos li-

${ }^{5}$ Los autores señalan que la deliberación es el camino más apropiado para los ciudadanos para resolver colectivamente los desacuerdos morales no sólo respecto a las políticas públicas, sino respecto a la forma en que dichas políticas deben ser adoptadas. La deliberación no atiende exclusivamente los resultados de una discusión, sino también a la forma en que se deciden los medios requeridos para alcanzar acuerdos comunes.

${ }^{6}$ Véase Max Weber (1984). 
berales por medio de su insistencia en que la democracia no interfiera con el dominio de la moral constituida por esos derechos, por lo que recibe el nombre de democracia liberal, democracia constitucional o democracia representativa (Nino, 1997:103). De acuerdo con las posturas de tipo liberal, el fundamento moral de los derechos, y por esa razón los derechos mismos, queda protegido ante cuestiones de cualquier tipo, ya que los mismos se corresponden con intereses específicos.

La segunda concepción es vista como opuesta a la liberal, y recibe el nombre de democracia populista, democracia social o democracia participativa. En ella lo que se busca es una transformación de las preferencias autointeresadas de los sujetos en otras que tengan mayor relación con posturas imparciales. Resulta claro que el lugar que se concede a la moral como medio de legitimación de las decisiones es lo que marca la diferencia entre estas distintas posturas.

El máximo exponente de la teoría liberal, John Rawls, señala que cualquier individuo, sociedad o Estado mantiene ciertos lineamientos sobre los que lleva a cabo sus propios planes o fines específicos. La facultad de realizar esos proyectos es lo que se conoce como su razón, y depende de sus facultades intelectuales y morales (Rawls, 1996:247). Es por eso que a todo individuo se le reconoce la capacidad de expresar sus razones y mantener principios morales individuales en los que pueda basarse para exteriorizar sus puntos de vista. Según esta postura, la opinión de los otros puede resultar beneficiosa para fortalecer la imparcialidad, pero el razonamiento individual está por encima de las decisiones colectivas.

A diferencia de lo expuesto por los autores del liberalismo, la segunda concepción señala que la legitimidad del derecho viene dada por las condiciones en que fue desarrollada la legislación, que responden a una serie de argumentos (Habermas, 1988:21). O sea, en este marco, las condiciones en las que se crea y aplica un ordenamiento tienen que ser consideradas como legítimas y es esto lo que determina su grado de validez (Cortina, 1988:69-70). Tales condiciones vendrán dadas a través de un procedimiento público comunicativo por medio del cual sean expuestos todos los puntos de vista (Habermas, 1998:311). De ahí que se apoye en el modo en que se da la comunicación, que es 
la que puede dotar de legitimidad al proceso político y generar de esta manera resultados racionales (Habermas, 1994:10).

De acuerdo con lo anterior, el espacio de la opinión pública se reproduce a través de la acción comunicativa que sólo exige dominar un lenguaje natural, ajustándose a la "inteligibilidad general de la práctica comunicativa cotidiana" (Habermas, 1998: 440). Esta práctica comunicativa cotidiana encuentra un entorno en el que se desarrolla y que ha sido denominado el mundo de la vida. El concepto suele relacionarse con el medio en el que se lleva a cabo el intercambio de las distintas concepciones de los individuos que forman la sociedad (Vallespín, 2001:14-24). ${ }^{7}$

Es importante destacar que este tipo de posturas reconocen la relevancia de la deliberación como proceso por medio del cual se puede llegar a decisiones imparciales, pero no olvidan que determinadas cuestiones pueden ser mejor resueltas mediante el razonamiento individual o, en todo caso, mediante una deliberación que reconozca la importancia superior de intereses subjetivos o de grupo (Ackerman, 1989:5-22). ${ }^{8}$

Ahora bien, de lo dicho hasta ahora puede señalarse que por lo que respecta a la conexión entre derecho y moral existen distintas alternativas, pero dicha relación cobra un sentido importante en las posturas en que la deliberación pretende legitimar las decisiones. La pretensión de corrección de Alexy guarda una intensa relación con los argumentos en los que se basan las teorías de la deliberación política, ya que para él, "la pretensión de corrección implica la pretensión de justificabilidad" (Alexy, 1998:131-133), razón por la cual el derecho y la moral se conectan en el momento de buscar que una decisión sea legítima mediante los procedimientos adecuados para ello.

Esto convierte a las propuestas de democracia deliberativa en alternativas viables y deseables, ya que conllevan un mayor grado de

\footnotetext{
${ }^{7} \mathrm{El}$ autor explica que por mundo de la vida puede entenderse "el lugar donde se produce el conjunto de interpretaciones intersubjetivas que constituyen un núcleo común de conocimientos implícitos, contribuyen a dotar de sentido a la existencia y constituyen el horizonte de cualquier entendimiento cognitivo y práctico".

${ }^{8}$ En este trabajo se hace una diferencia entre el ámbito puramente individual, en el que las decisiones morales no dependen de la utilización del diálogo, y el contacto del individuo con el mundo exterior, donde el diálogo es necesario como expresión del ciudadano responsable.
} 
legitimidad y una impronta más democrática que la democracia liberal y procedimental. Las posturas que defienden la deliberación reconocen que los individuos tienen las capacidades suficientes como para lograr un mutuo entendimiento bajo procesos comunicativos, y de esta manera los consideran una pieza clave en la que debe basarse todo proceso legitimador de la democracia (Cohen, 2001:237). La educación cívica es en todas estas teorías un elemento fundamental con el que se logra promover la participación y la deliberación (Dahl, 1988:12-17).

En esta línea, algunas de las propuestas actuales, en las que no nos detendremos, promueven el fortalecimiento de la democracia mediante la promoción de mecanismos deliberativos concretos. En términos generales, tales trabajos se orientan a la creación de estructuras e instituciones en las que se reflejen las diferentes opiniones ciudadanas y se fomenten canales públicos de participación. En definitiva, el ejercicio de la política debe considerarse como algo adecuado a las preferencias de los individuos y no como el simple desarrollo de una serie de medidas tomadas de antemano y al margen de sus consideraciones.

No se pretende con estos razonamientos indicar una solución definitiva a los problemas que aquejan a la democracia, ni siquiera creemos que sea posible tomando en cuenta que muchas de las propuestas no han sido puestas en práctica. Sin embargo, sí quisiera señalar con Manuel Aragón que "el derecho es inconciliable con el absolutismo teórico en cuanto que se trata de un saber que no se basa en criterios cerrados o plenamente exactos, sino en proposiciones siempre relativas" (Aragón, 1989:135-138).

En nuestra opinión, las propuestas que tienen que ver con el incremento de la participación y el fomento de la deliberación pueden ayudar a superar la crisis de legitimidad en el seno de las sociedades democráticas.

\section{Bibliografía}

Ackerman, Bruce (1989), "Why Dialogue?", The Journal of Philosophy, vol. 86, núm. 1, enero, pp. 5-22.

Alexy, Robert (1998), "Sobre las relaciones necesarias entre el derecho y la moral", en Rodolfo Vázquez (comp.), Derecho y moral. Ensayos sobre un debate contemporáneo, Barcelona, Gedisa. 
Almond, Gabriel y Sidney Verba (1970), La cultura cívica: estudio sobre la participación política en cinco naciones, Madrid, Fundación FOESSA.

Aragón, Manuel (1989), Constitución y democracia, Madrid, Tecnos.

Asís Roig, Rafael de (2001), Sobre el concepto y el fundamento de los derechos. Una aproximación dualista, Madrid, Dykinson.

Bachrach, Peter (1973), Crítica de la teoría elitista de la democracia, Buenos Aires, Amorrortu.

Bobbio, Norberto (1993), Igualdad y libertad, Barcelona, Paidós, Universidad Autónoma de Barcelona. (1985), El futuro de la democracia, Barcelona, Plaza \& Janés. , Nicola Matteucci y Gianfranco Pasquino (1998), Diccionario de Política, vol. 2, México, Siglo XXI.

Cohen, Joshua (2001), “Democracia y libertad”, en Jon Elster (comp.), La democracia deliberativa, Barcelona, Gedisa.

Coleman, James S. (2001), “Capital social y creación de capital humano", Zona Abierta, núm. 94/95, pp. 47-81.

Constant, Benjamin (1989), “De la libertad de los antiguos comparada con la de los modernos", en Escritos políticos, Madrid, Centro de Estudios Constitucionales.

Cortina, Adela (1988), "La moral como forma deficiente de derecho", Doxa, núm. 5, pp. 60-70.

Dahl, Robert (1999), La democracia. Una guía para los ciudadanos, Madrid, Taurus.

(1988), “Por qué la igualdad política?”, Claves de Razón Práctica, núm. 88, pp. 12-17.

Fernandez García, Eusebio (1996), “Estado, sociedad civil y democracia”, en Rafael Asís Roig (ed.), Valores, derechos y Estado a finales del siglo XX, Madrid, Dykinson.

García-Marzá, Domingo (2003), "Política deliberativa y sociedad civil: el valor de la participación”, en Jesús Conill y David A. Crocker (ed.), Republicanismo y educación cívica. ¿Más allá del liberalismo?, Granada, Comares.

(1996), "Un modelo deliberativo de democracia participativa”, Arbor, núm. 608, agosto, pp. 97-121. 
Gargarella, Roberto y Félix Ovejero (2000), “Democracia representativa y virtud cívica", Claves de Razón Práctica, núm. 105, septiembre, pp. 10-18.

Giner, Salvador (2000), "Cultura republicana y política del porvenir", en Salvador Giner (coord.), La cultura de la democracia: el futuro, Barcelona, Ariel. y Sebastián Sarasa (1995), “Altruismo cívico y política social”, Leviatán, núm. 61, otoño, pp. 71-86.

Gutmann, Amy y Dennis Thompson (1997), Democracy and its Discontents, Harvard, Harvard University Press.

Habermas, Jürgen (2004), “Derechos humanos y soberanía popular: las versiones liberal y republicana", en Félix Ovejero, J.J Martí, Roberto Gargarella (comps.), Nuevas ideas republicanas. Autogobierno y libertad, Barcelona, Paidós. (1998), Facticidad y validez. Sobre el derecho y el Estado democrático de derecho en términos de la teoría del discurso, Madrid, Trotta. (1997), "El nexo interno entre Estado de derecho y democracia”, en José Antonio Gimbernat (ed.), La filosofía moral y política de Jürgen Habermas, Madrid, Biblioteca Nueva. (1994), Tres modelos de democracia. Sobre el concepto de una política deliberativa, vol. 43, p. 10, Valencia, Centro de Semiótica y Teoría del Espectáculo.

(1988), “Cómo es posible la legitimidad por vía de legalidad?", Doxa, núm. 5, pp. 21-45.

Laporta, Francisco (2001), "Los problemas de la democracia deliberativa", Claves de Razón Práctica, núm. 109, pp. 22-28. (2000), "El cansancio de la democracia", Claves de Razón Práctica, núm. 99, pp. 21-26.

Lucas Verdú, Pablo y Pablo Lucas Murillo de la Cueva (2001), Manual de derecho político, vol. 1, Madrid, Tecnos.

Merino, Mauricio (1995), La participación ciudadana en la democracia, México, Cuadernos de Divulgación de la Cultura Democrática, núm. 4, Instituto Federal Electoral.

Milbrath, Lester y M.L. Goel (1977), Political Participation, Boston, Rand Mcnally. 
Nino, Carlos Santiago (1997), La constitución de la democracia deliberativa, Barcelona, Gedisa. (1986), “La participación como remedio a la llamada 'crisis de la democracia', en Luis Aznar (ed.), Alfonsín. Discursos sobre el discurso, Buenos Aires, Eudeba.

(1983), Introducción al análisis del derecho, Madrid, Ariel.

Paramio, Ludolfo (1996), "La sociedad desconfiada”, Leviatán, núm. 66, invierno, pp. 103-114.

Pateman, Carole (1970), Participation and Democratic Theory, Cambridge, University Press.

Pettit, Philip (2001), "Republican Freedom and Contestatory Democratization", en Ian Shapiro y Casiano Hacker-Cordón, Democracy's Value, Cambridge University Press.

Putnam, Robert D. (2001), “La comunidad próspera. El capital social y la vida pública", Zona Abierta, núms. 94/95, pp. 89-104.

Rawls, John (1996), El liberalismo político, Barcelona, Crítica.

Rodríguez Palop, María Eugenia (2002), La nueva generación de derechos humanos. Origen y justificación, Madrid, Dykinson.

Rousseau, Jean Jacques (1988), El contrato social, Madrid, Tecnos.

Rubio Carracedo, José (2000), “¿Cansancio de la democracia o acomodo de los políticos?", Claves de Razón Práctica, núm. 105, pp. 76-82.

Sartori, Giovanni (1999), "En defensa de la representación política", Claves de Razón Práctica, núm. 91, abril, pp. 2-6. (1993), ¿Qué es la democracia?, México, Instituto Federal Electoral, Tribunal Federal Electoral.

Schattschneider, E. (1960), The Semisovereign People. A Realist's View of Democracy in America, Nueva York, Holt, Rinehart and Winston.

Sen, Amartya (2004), "El ejercicio de la razón pública", Letras Libres, núm. 65, México, mayo, pp. 12-20. (2001), "La democracia como valor universal", Revista Istor de Historia Universal, año 1, núm. 4, México, Centro de Investigación y Docencia Económicas, pp. 10-28.

Vallespín, Fernando (2001), “Habermas en doce mil palabras”, Claves de Razón Práctica, núm. 114, pp. 14-24. 
Estudios Fronterizos, VOL. 10, NÚM. 20, JULIO-DICIEMBRE 2009

Vallespín, Fernando (1997), “Reconciliación a través del derecho? Apostillas a facticidad y validez de Jürgen Habermas", en José Antonio Gimbernat (ed.), La filosofía moral y politica de Jürgen Habermas, Madrid, Biblioteca Nueva.

Weber, Max (1984), Economía y sociedad, México, Fondo de Cultura Económica. 